\title{
Design and Analysis of Shunt Active Power Filter (SAPF) for Non Linear and Unbalanced Loads
}

\author{
Kiran Yaddanapudi, Pannala Krishna Murthy
}

\begin{abstract}
Increasing power demand in present situation has to comply with the power generation. Generated power has to meet the quality standards. With the introduction of nonlinear loads like static power converters inject harmonics into the system which effect operation of the system adversely. In order to improve the performance of the system these harmonics are to be mitigated and reactive power need to be compensated. In the proposed work a Shunt Active Power Filter (SAPF) is designed to compensate reactive power and the behavior of the system is analyzed by introducing reverse harmonic current.
\end{abstract}

Keywords: Shunt Active Power Filter, Instantaneous Power Theory, Clarkes Transformation, Total Harmonic Distortion (THD), Pulse Width Modulation.

\section{INTRODUCTION}

Advent of power electronic technology has given scope for development of non linear loads such as diode-rectifiers, thyristor converters, adjustable speed drives, furnaces, computer power supplies, un-interruptible power supplies, etc. which are economical, flexible and energy efficient but effect the power quality by producing voltage harmonics from current harmonics and consume extra reactive power.[1] Extensive research has been done on active filters since their inception in 1970. Improvements in power electronics technology has made engineers to use active filters practically. Many numbers of shunt active filters made up of Pulse Width Modulation (PWM) inverters using insulated biplolar transistors (IGBT) or gate turn-off (GTO) thyristors are operating successfully. Usually, passive LC filters are put to use to mitigate line current harmonics and for power factor improvement. But there are so many drawbacks of passive filters such as they are bulky in size, compensation is fixed, and causing resonance. To overcome the drawbacks of passive filters, active power filters were designed. [3]

Modern active filters are better in terms of their behavior, small size, and their flexibility in application than traditional passive filters. In addition, the active filters are available at lower cost with low operating loss, than passive filters. [2]

Revised Manuscript Received on December 05, 2020.

* Correspondence Author

Kiran Yaddanapudi*, Electrical and Electronics Engineering, Jawaharlal Nehru Technological University Hyderabad, Hyderabad, INDIA. Email: kiran045@gmail.com

Pannala Krishna Murthy, Electrical and Electronics Engineering, Khammam Institute of Technology and Sciences, Khammam, INDIA. Email: krishnamurthy.pannala@gmail.com

(C) The Authors. Published by Blue Eyes Intelligence Engineering and Sciences Publication (BEIESP). This is an open access article under the CC BY-NC-ND license (http://creativecommons.org/licenses/by-nc-nd/4.0/)

\section{ACTIVE FILTERS}

Active Power Filters (APF) are used in low power $(<100 \mathrm{kVA})$, medium power (100kVA-10MVA) and high power (>10 MVA) applications [7]. The power circuit of Active Power Filters is generally made up of by a DC Capacitor Unit, DC/AC converter and Harmonic filter.

\section{A. DC Capacitor Unit}

The purposes of DC Capacitor Unit are twofold, firstly during steady state a DC Voltage is maintained with small ripple. Secondly during transient period it supplies real power difference between load and source behaving like an energy storage element.

\section{B. DC/AC Converter}

The purposes of DC Capacitor Unit are twofold, firstly during steady state a DC Voltage is maintained with small ripple. Secondly during transient period it supplies real power difference between load and source behaving like an energy storage element.

\section{Harmonic Filter}

An inductance for output filtering of VSI is used to mitigate the harmonic at various frequencies. Attenuation of switching ripple currents with different combinations of $\mathrm{L}$ and $C$ filters was examined in [8]. A malfunction or shutdown of a rectifier happens if it has extra low inductance characteristic or connected with load having high frequency input current with phase control. To reduce the rising rate of load input current for above load a reactor of $3-5 \%$ has to be connected at the input side of the load. [9].For reactive power compensation and mitigation of harmonics LC passive filter is used in [10]. To attain required damping of switching harmonics smaller inductors can be employed in LCL-filter presented in [11] when compared with L-filter because of advantages in costs and dynamic performance. [5]

\section{TYPES OF ACTIVE POWER FILTERS}

Active Power Filters can be connected in several power circuit configurations. Generally, they are classified into three categories, they are Shunt Active Power Filters, Series Active Power Filters and Hybrid Active Power Filters [12][13].

Published By:

Blue Eyes Intelligence Engineering 


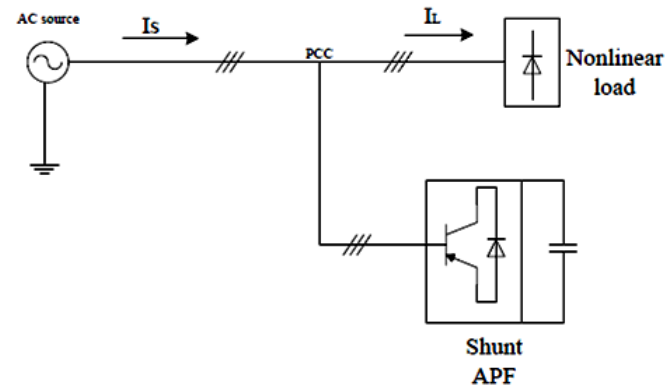

Fig. 1.Shunt Active Power Filter

\section{A. Shunt Active Power Filter}

This class of filter configurations is the most important and most widely used type in active filtering applications. Shunt Active Power Filter is shown in Fig 1. Its purpose is to cancel the load current harmonics fed to the supply. Balancing three phase currents and compensation of reactive power are its contributions. To compensate for system losses a small amount of active fundamental current plus the compensation current is supplied by Parallel filters. For wide range of power ratings a number of filters can be connected in parallel to get higher currents.

\section{B. Series Active Power Filter}

The active filter in this configuration produces a Pulse Width Modulated voltage waveform which is added or subtracted, on an instantaneous basis, to/from the supply voltage to maintain a pure sinusoidal voltage waveform across the load. In general Series active filters are used hardly in industries, when compared to parallel active filters. High current ratings in the secondary side of the coupling transformer since these filters have to carry high load currents is the main drawback. These are employed for balancing three phase voltages and to reduce the voltage harmonics. These are preferred for voltage sensitive devices.

\section{Hybrid Active Power Filters}

These configurations can overcome the technical limitations of conventional Active Power Filters. Hybrid APFs are made up with both APFs and passive filters. With the advantages of both passive and active filters cost-effective solutions with improved performance were provided by Hybrid APFs. In addition to conventional APF a low cost passive high pass filter is used in this scheme. These two filters divide the task of filtering between them. Lower order harmonics were handled by APF while the higher order harmonics by passive filters. Improved filtering performance of higher order harmonics with cost effective low order harmonics mitigation are provided by hybrid APF. [4]

\section{INSTANTANEOUS POWER THEORY}

The control of active power filters in real time is done by the $p-q$ theory or instantaneous power theory in time domain; it can be used either in steady-state or transient state also for generic voltage and current waveforms. The p-q theory performs a Clarke transformation of a stationary reference system of coordinates $\mathrm{a}-\mathrm{b}-\mathrm{c}$ to a reference system of coordinates $\alpha-\beta-0$, also stationary. In ABC coordinates axes are set on the same plane, displaced from each other by $120^{\circ}$.

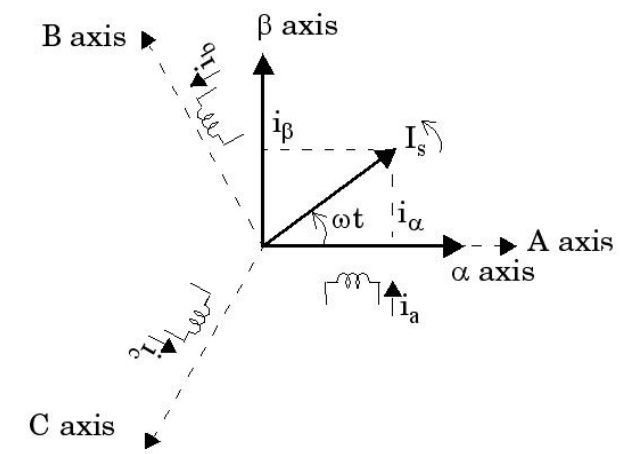

Fig. 2.abc to $\alpha \beta 0$ Transformation

$$
\begin{aligned}
& {\left[\begin{array}{l}
i_{\alpha} \\
i_{\beta} \\
i_{0}
\end{array}\right]=\sqrt{\frac{2}{3}}\left[\begin{array}{ccc}
1 & -\frac{1}{2} & -\frac{1}{2} \\
0 & \frac{\sqrt{3}}{2} & -\frac{\sqrt{3}}{2} \\
\frac{1}{\sqrt{2}} & \frac{1}{\sqrt{2}} & \frac{1}{\sqrt{2}}
\end{array}\right]\left[\begin{array}{l}
i_{a} \\
i_{b} \\
i_{c}
\end{array}\right]} \\
& {\left[\begin{array}{l}
i_{a} \\
i_{b} \\
i_{c}
\end{array}\right]=\sqrt{\frac{2}{3}}\left[\begin{array}{ccc}
1 & 0 & \frac{1}{\sqrt{2}} \\
-\frac{1}{2} & \frac{\sqrt{3}}{2} & \frac{1}{\sqrt{2}} \\
-\frac{1}{2} & -\frac{\sqrt{3}}{2} & \frac{1}{\sqrt{2}}
\end{array}\right]\left[\begin{array}{l}
i_{\alpha} \\
i_{\beta} \\
i_{0}
\end{array}\right]} \\
& {\left[\begin{array}{l}
v_{\alpha} \\
v_{\beta} \\
v_{0}
\end{array}\right]=\sqrt{\frac{2}{3}}\left[\begin{array}{ccc}
1 & -\frac{1}{2} & -\frac{1}{2} \\
0 & \frac{\sqrt{3}}{2} & -\frac{\sqrt{3}}{2} \\
\frac{1}{\sqrt{2}} & \frac{1}{\sqrt{2}} & \frac{1}{\sqrt{2}}
\end{array}\right]\left[\begin{array}{l}
v_{a} \\
v_{b} \\
v_{c}
\end{array}\right]} \\
& {\left[\begin{array}{l}
v_{a} \\
v_{b} \\
v_{c}
\end{array}\right]=\sqrt{\frac{2}{3}}\left[\begin{array}{ccc}
1 & 0 & \frac{1}{\sqrt{2}} \\
-\frac{1}{2} & \frac{\sqrt{3}}{2} & \frac{1}{\sqrt{2}} \\
-\frac{1}{2} & -\frac{\sqrt{3}}{2} & \frac{1}{\sqrt{2}}
\end{array}\right]\left[\begin{array}{l}
v_{\alpha} \\
v_{\beta} \\
v_{0}
\end{array}\right]}
\end{aligned}
$$

where $i_{a}, i_{b}, i_{c}$ are the load currents and $v_{a}, v_{b}, v_{c}$ are the load voltages

The equations of active, reactive and zero-sequence powers are defined as in equations.

$$
\begin{aligned}
& p=v_{\alpha} i_{\alpha}+v_{\beta} i_{\beta} \\
& q=v_{\alpha} i_{\beta}-v_{\beta} i_{\alpha} \\
& p_{0}=v_{0} i_{0}
\end{aligned}
$$

The currents, voltages and powers in the $\alpha-\beta$ system can be decomposed in mean and alternating values, in terms of the fundamental and harmonic components, as in equation

$$
x=\bar{x}+\tilde{x}
$$

Where $\mathrm{x}$ can be powers, currents, or voltages.

The power components have the following physical meaning [14]

$p_{0}$ Zero Sequence Power

$\bar{p}$ Mean Value of the Instantaneous Real Power

$\tilde{p}$ Alternating Value of the Instantaneous Real Power

$\bar{q}$ Mean Value of the Imaginary Power

$\tilde{q}$ Alternating Value of the Imaginary Power

The powers required to be compensated by the APF are calculated as in equation
Blue Eyes Intelligence Engineering and Sciences Publication (C) Copyright: All rights reserved.

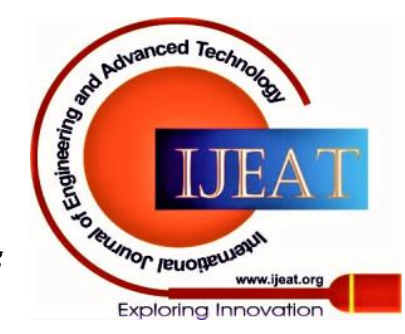


$\left[\begin{array}{l}\tilde{p} \\ q\end{array}\right]=\left[\begin{array}{cc}\overline{v_{\alpha}} & \overline{v_{\beta}} \\ 0 & 0\end{array}\right]\left[\begin{array}{c}\tilde{\iota_{\alpha}} \\ \tilde{\tau_{\beta}}\end{array}\right]+\left[\begin{array}{cc}0 & 0 \\ \overline{-v_{\beta}} & \overline{v_{\alpha}}\end{array}\right]\left[\begin{array}{l}i_{\alpha} \\ i_{\beta}\end{array}\right]$

The reference currents are calculated by adding the active power required to regulate the DC bus voltage, ploss to the alternative value of instantaneous real power from the following equation

$\left[\begin{array}{l}i_{\alpha}^{*} \\ i_{\beta}^{*}\end{array}\right]=\frac{1}{\Delta} T\left[\begin{array}{l}0 \\ \bar{q}\end{array}\right]+\frac{1}{\Delta} T\left[\begin{array}{c}\tilde{p}+p_{\text {loss }} \\ \tilde{q}\end{array}\right]$

Where $\Delta=\overline{v_{\alpha}^{2}}+\overline{v_{\beta}^{2}}$ and $T=\left[\begin{array}{cc}\overline{v_{\alpha}} & -\overline{v_{\beta}} \\ \overline{v_{\beta}} & \overline{v_{\alpha}}\end{array}\right]$

From (9) the APF computes $\tilde{p}$ using the harmonic components of the currents while $q=\bar{q}+\tilde{q}$ are computed using the load current, including AC and DC components, according to Fig. 3.

Transformation of load currents from three-phase abc to $\alpha \beta 0$ components is done using Clarke transformation, as in (11).

$\left[\begin{array}{l}i_{a}^{*} \\ i_{b}^{*} \\ i_{c}^{*}\end{array}\right]=\sqrt{\frac{2}{3}}\left[\begin{array}{ccc}1 & 0 & \frac{1}{\sqrt{2}} \\ -\frac{1}{2} & \frac{\sqrt{3}}{2} & \frac{1}{\sqrt{2}} \\ -\frac{1}{2} & -\frac{\sqrt{3}}{2} & \frac{1}{\sqrt{2}}\end{array}\right]\left[\begin{array}{c}i_{\alpha}^{*} \\ i_{\beta}^{*} \\ i_{0}^{*}\end{array}\right]$

Shunt active power filter provides compensation strategy based on the $\mathrm{p}-\mathrm{q}$ theory of all undesired power components $\left(p, p_{0}\right.$ and $\left.q\right)$. [4]

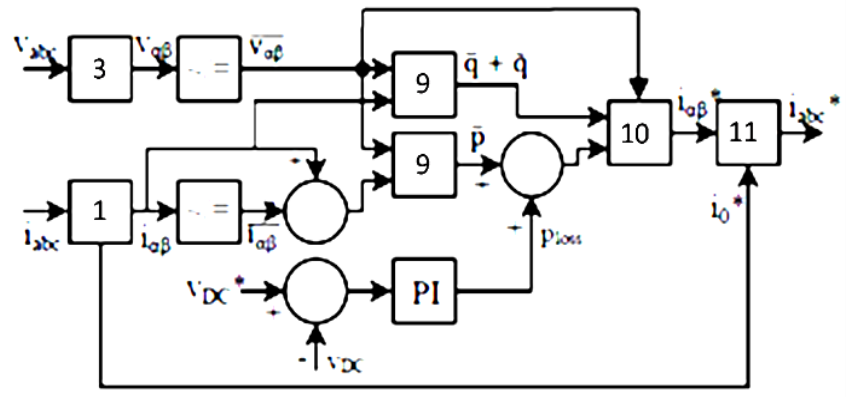

Fig. 3. Proposed Control Strategy

\section{DESIGN OF SHUNT ACTIVE POWER FILTER USING MATLAB}

A Shunt Active Power Filter is designed with MATLAB/Simulink as shown in the Fig. 4.

The model consists of a three phase source supplying a phase to phase RMS voltage of 400 Volts, $50 \mathrm{~Hz}$ with $\mathrm{Yg}$ internal connection having a source resistance $\mathrm{Rs}=0.001 \mathrm{Ohms}$, source inductance Ls=1e-8Henries, series resistance $\mathrm{R}=0.01 \mathrm{Ohms}$ and series inductance of $\mathrm{L}=1 \mathrm{e}-6$ Henries.

Two types of loads are connected to the system, they are firstly a rectifier with a load resistance of $10 \mathrm{Ohms}$ and a three phase unbalanced star connected resistive load with 10 Ohms, 20 Ohms \& 30 Ohms in the respective a, b, \& c phases.

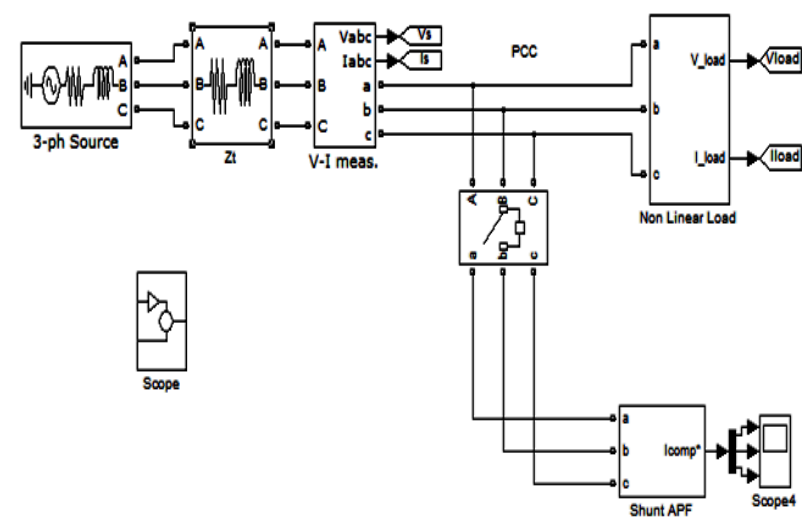

Fig. 4.Simulink Model of Shunt Active Power Filter

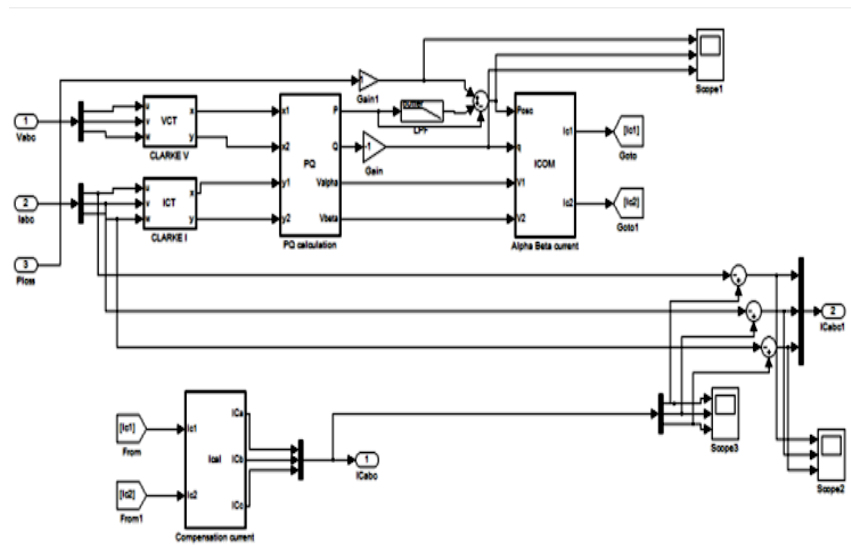

Fig. 5.Simulink Model of Control of Shunt Active Power Filter

\section{SIMULATION RESULTS}

Shunt Active Power Filter MATLAB model is simulated by connecting non linear load from starting and the unbalanced load at $\mathrm{T}=0.1$ seconds with a sampling time of Ts=5e-6seconds without connecting filter and the performance of the system is analyzed by the output waveforms and the Total Harmonic Distortion (THD) of the signals are calculated. The output waveforms are shown in Fig. 6 \& Fig. 7.

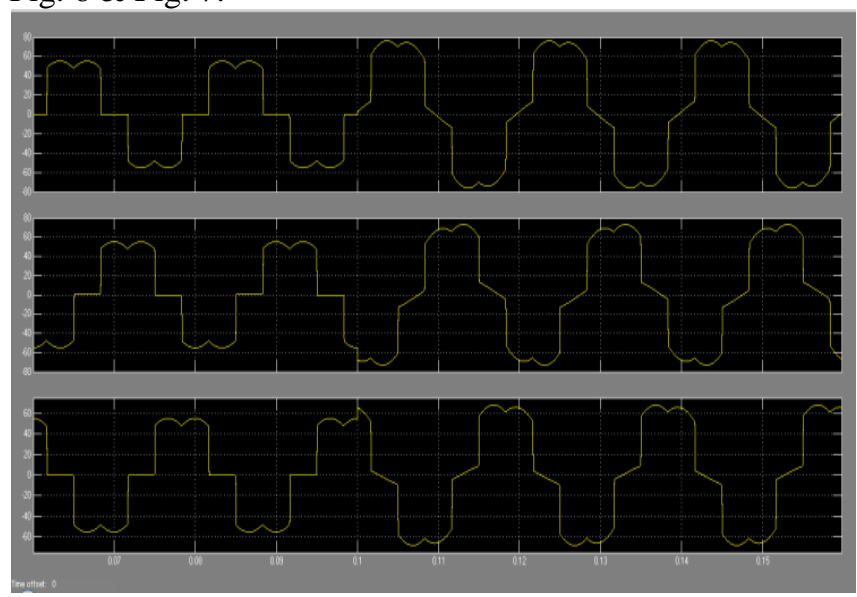

Fig. 6.Three Phase Supply Current without Filter

Published By:

Blue Eyes Intelligence Engineering and Sciences Publication

(c) Convriaht: All riahts reserved.

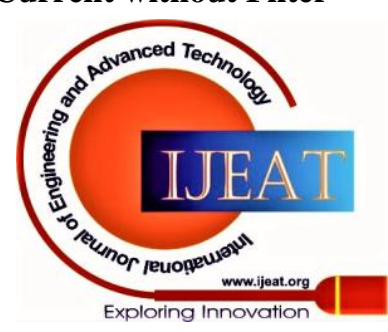




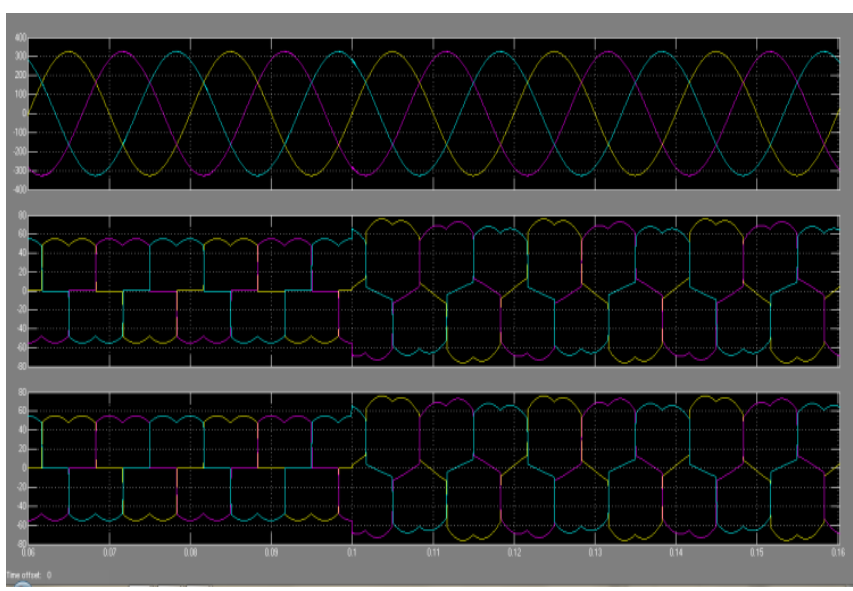

Fig. 7. Three Phase Load Voltage, Load Current and Supply Current without Filter

Now Shunt Active Power Filter is connected to the model with a Transition time of $\mathrm{T}=0.01$ seconds and the model is simulated again, it was observed that at $\mathrm{T}=0.01$ seconds the filter got turned on and the process of mitigating current harmonic has started and the performance of the system started to improve. The results from the simulation were observed from the waveforms and the Total Harmonic Distortion (THD) of the signals. The output waveforms after connecting the filter were shown in Fig. 8, Fig. 9 \& Fig.10.

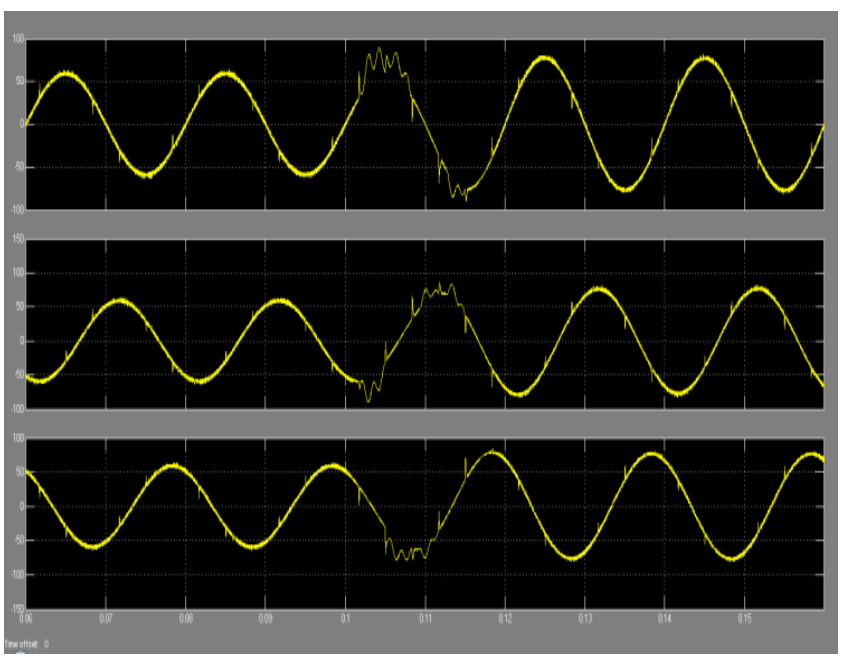

Fig. 8. Three Phase Supply Current with Filter

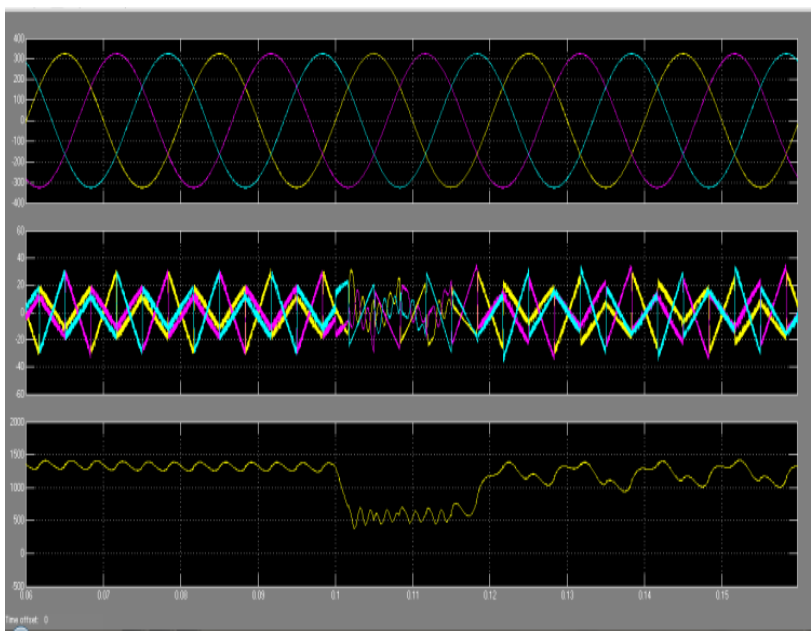

Fig. 9. Three Phase Supply Voltage, Filter Current and DC Voltage with Filter

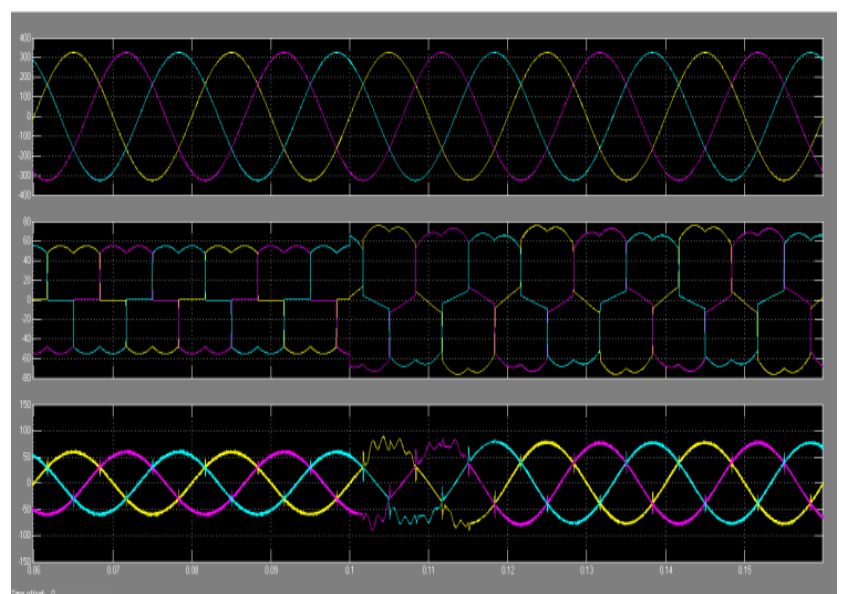

Fig. 10. Three Phase Load Voltage, Load Current and Supply Current with Filter

Table- I: Total Harmonic Distortion of Supply Current with and without filter for Non Linear and Unbalanced

Loads.

\begin{tabular}{|c|c|c|c|}
\hline Signal & $\begin{array}{c}\text { Signal } \\
\text { Number }\end{array}$ & $\begin{array}{c}\text { THD in \% without } \\
\text { filter }\end{array}$ & $\begin{array}{c}\text { THD in \% with } \\
\text { filter }\end{array}$ \\
\hline \multicolumn{4}{|c|}{ NON LINEAR LOAD \& UNBALANCED LOAD } \\
\hline \multirow{3}{*}{ Is } & 1 & 21.88 & 3.31 \\
\cline { 2 - 4 } & 2 & 23.11 & 3.79 \\
\cline { 2 - 4 } & 3 & 24.59 & 3.70 \\
\hline \multicolumn{3}{|c|}{ NON LINEAR LOAD } \\
\hline \multirow{3}{*}{ Is } & 1 & 30.26 & 4.60 \\
\cline { 2 - 4 } & 2 & 30.26 & 4.48 \\
\cline { 2 - 4 } & 3 & 30.26 & 4.60 \\
\hline
\end{tabular}

\section{CONCLUSIONS}

Shunt Active Power Filter (SAPF) model is simulated with MATLAB/Simulink and it is observed that with SAPF the Total Harmonic Distortion (THD) of the supply current (Is) is reduced from $21.88 \%$ to $3.31 \%$ for non linear load and unbalanced load and from $30.26 \%$ to $4.60 \%$ with only non linear load. So the performance of the system is improved by compensating reactive power and mitigating the harmonics.

\section{REFERENCES}

1. Hamza Bentria, "A Shunt Active Power Filter Controlled by Fuzzy Logic Controller for Current Harmonic Compensation and Power Factor Improvement" Journal of Theoretical and Applied Information Technology Vol. 32 No.1, october 2011, pp 1-10.

2. R.S.Udgave, Y.R.Atre, "Active Filters with Control based on the P-Q Theory", IOSR Journal of Electronics and Communication Engineering (IOSR-JECE), ISSN: 2278-2834, pp 27-30.

3. Hirofumi Akagi, "New Trends in Active Filters for Power Conditioning", IEEE Transactions on Industry Applications, Vol. 32 No. 6, November/December 1996, pp 1-11.

4. Anju Jacob, Babitha T Abraham, Nisha Prakash, Riya Philip, "A Review of Active Power Filters In Power System Applications" International Journal of Advanced Research in Electrical, Electronics and Instrumentation Engineering, Vol.3 Issue 6, JUne 2014, pp 1-9.

5. Akagi, H.; Kanazawa, Y.; Nabae, A. 1983. "Generalized Theory of the Instantaneous Reactive Power in Three- Phase Circuits", in Proc. IPEC-Tokyo'83 Int. Conf.Power Electronics, Tokyo, pp. 1375-1386.

6. Ahmet Teka, Lutfu Saribulut, M Emin Meral, Mehmet Tumay, "Active Power Filter: Review of Converter Topologies and Control Strategies" Gaji University Journal of Science, Vol. 24 No.2, pp 283-289.

7. Habrouk E., Darwish M., Mehta M.K., "Active power filters: A review", Electric Power Applications, IEE Proceedings, 147: 403-413, (2000).

\section{Published By:}

Blue Eyes Intelligence Engineering and Sciences Publication

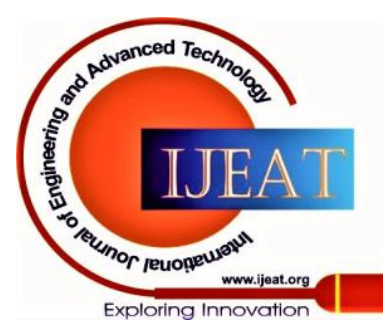


8. Routimo M., Tuusa H., "LCL type supply filter for active power filter, comparison of an active and a passive method for resonance damping" IEEE Power Electronics Specialists Conference, 2939- 2945, (2007).

9. Internet:http://www.ablerex- ups.com.sg/note.pdf, (2010).

10. Luo A., Shuai Z., Shen Z. J., Wenji Z., Xianyong X., "Design considerations for maintaining DC side voltage of hybrid active power filter with injection circuit", Power Electronics, IEEE Transactions., 24: 75-84, (2009).

11. Vodyakho Mi O. C. C., "Three-level inverter based shunt active power filter in three-phase three-wire and four-wire systems", IEEE transactions on power electronics, 24, (2009).

12. Zainal Salam, Tan Perng Cheng and Awang Jusoh, "Harmonics Mitigation Using Active Power Filter: A Technological Review", ELEKTRIKA, VOL. 8, NO. 2, 200.6, 17- 26.

13. [M.E-Habrouk, M.K.Darwish and P.Mehta, "Active power filters: A review”, IEEE Proc.-Elertr. Power Appl., Vol. 147, No. 5, September 2000

14. Afonso, J. A.l Freitas, N.J.S.; Martins, J. S. 2003. p-q “ Theory Power Components Calculations", IEEE International Symposium on Industrial Electronic, Rio de Janeiro, Brasil

\section{AUTHORS PROFILE}

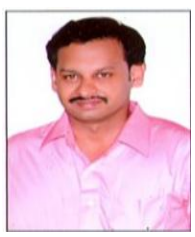

Kiran Yaddanapudi was born in 1980 in Kallur, India. He received the B.Tech in Electrical \& Electronics Engineering from Kakatiya University in 2001 and M.Tech in Embedded Systems in JNTUH, Hyderabad in 2011. He is at present pursuing Ph.D. in Department of EEE, JNTUH, Hyderabad. His research areas include Power Systems, Power Quality, HVDC and Filters.

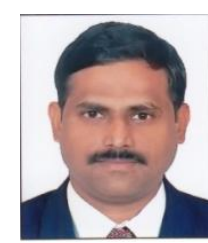

Pannala Krishna Murthy was born in Kakinada, India He secured his B.Tech. Degree from SSGMCE, Shegoan. He obtained Master's Degree and Doctoral Degree (Ph.D) from Jawaharlal Nehru Technological University Hyderabad, Kukatpally, Hyderabad. Presently he is working as Professor\& Principal in Khammam Institute of Technology and Sciences, Khammam. He got more than 40 Technical Publications at National \& International level and guided over 25 PG and 40 UG projects. He visited Singapore and chaired a session in the International Conference on Electrical Engineering: Theory and Application (ICEETA 2014). He has been teaching variety of subjects like Electrical Circuits, Electrical Measurements, Power Systems, and HVDC Transmission. At present he is working on the problems of HVDC System Fault Analysis and Power Quality.

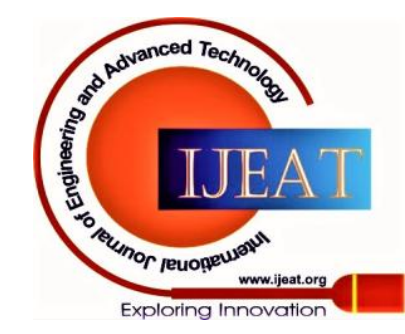

